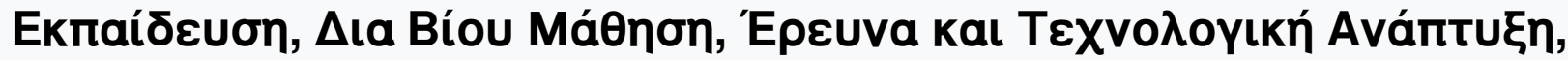 Kaıvotouía kal Oıkovouía
}

Tóp. 1 (2016)

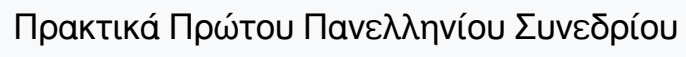

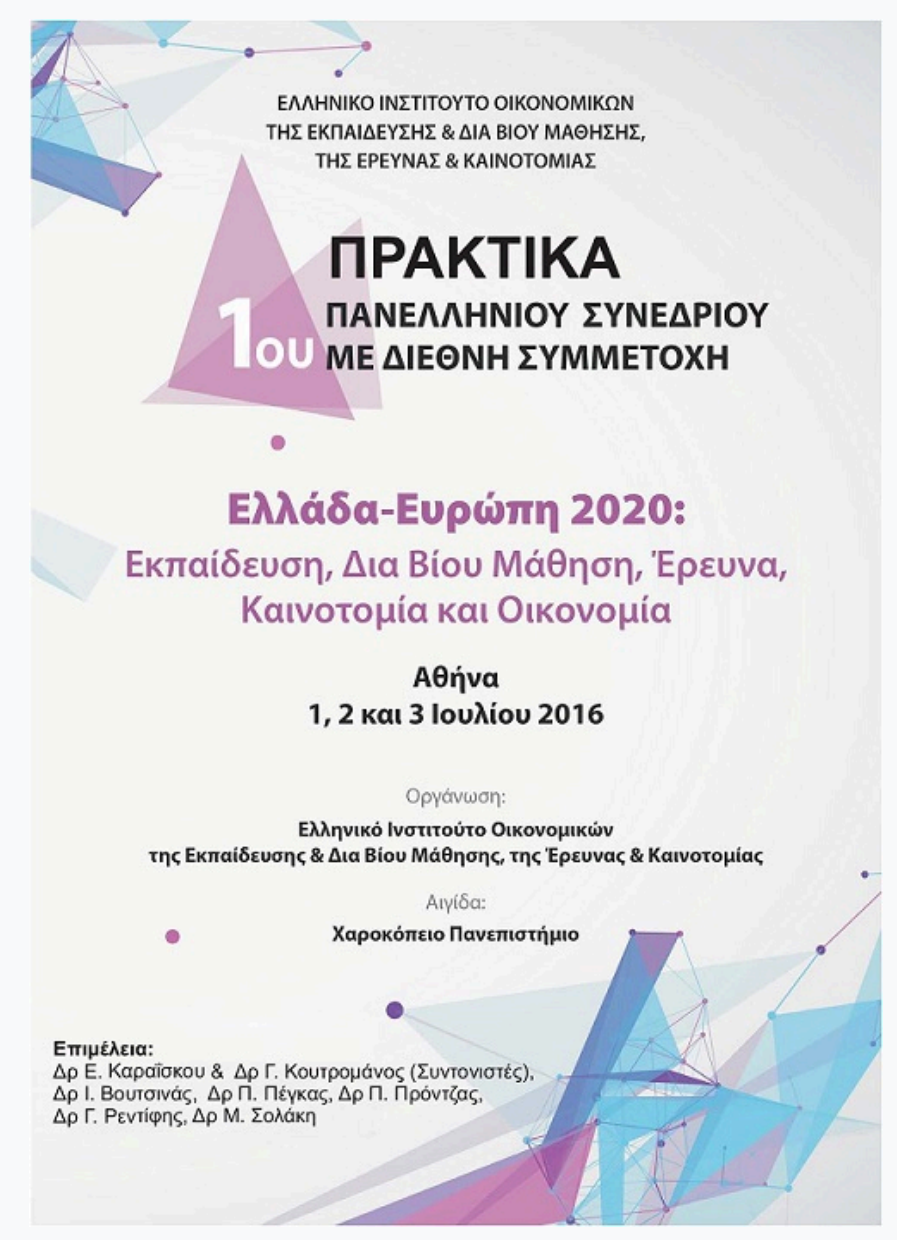

Private or public school advantage? Evidence from 40 countries using PISA 2012-Mathematics

Chris Sakellariou

doi: $10.12681 /$ elrie.820 


\title{
Private or public school advantage? Evidence from 40 countries using PISA 2012-Mathematics
}

\author{
Chris Sakellariou \\ acsake@ntu.edu.sg \\ Department of Economics \\ Humanities and Social Sciences \\ Nanyang Technological University, Singapore
}

\begin{abstract}
It is known that in most countries, students in private schools outperform students in public schools in international assessments. However, assessing the true effect of private school attendance requires addressing selection and sorting issues on both observables and unobservables. The existing empirical evidence on the private school effect mostly covers OECD and Latin American countries, with little evidence on other parts of the world. There is recent emerging country specific evidence doubting the existence of a private school advantage. I use PISA 2012 data for Mathematics and two different methodologies to derive baseline and bias-corrected estimates of the private-dependent and independent school effect for 40 countries. A robust private school advantage if found only in a handful of countries. Public schools generally perform equally well as private subsidised schools and outperform independent schools. Accounting for both peer effects and selection is necessary when evaluating school effectiveness, especially in the case of independent schools.
\end{abstract}

Keywords: School choice, private school advantage, PISA, unobservables.

\section{Introduction}

Parents decide whether to enrol their children to a private instead of a public school by assessing the benefits and costs associated with this decision. Perceived benefits relate to more autonomy and flexibility in deciding curricula, more resources, better peer groups and a safer school environment, among others. Private schools tend to attract not only students from more privileged backgrounds, but also better performing students (OECD, 2011).

There is definite evidence that, based on a simple comparison without accounting for student background, private school students perform better in the overwhelming majority of countries and the raw PISA score difference ranges from only a few points to more than 100 points; in a minority of countries public schools outperform private schools. After accounting for student socioeconomic background and other observables, the evidence is mixed.

Assessing the true effect of private school attendance hinges on addressing both the effect of observable covariates (associated with student and family background characteristics and school demographics) and selection effects. There is sorting of students into private and public schools; for example, students from better socioeconomic backgrounds enrolling in private schools. This results in endogeneities, since more privileged/higher ability private school students achieve 
better results, which in turn leads to an overestimation of the private school effect (French and Kingdon, 2010; Mcloughlin, 2013). One would then need a suitable measure or proxy for ability, which may prove elusive; such problems magnify if the objective is to estimate such effects across countries rather than for a single country, since then consistency and comparability issues are important.

The empirical evidence of effectiveness of private vs. public schools is based on two different strands of literature. The older strand, is based on randomized voucher studies (see for example, Coleman \& Hoffer, 1987; Coleman, Hoffer \& Kilgore, 1982), and generally finds gains for students switching to private schools. However, there is no lack of criticism and objections to the conclusion that such studies are superior. Lubienski, Weitzel and Lubienski (2009) provide an extensive review of the literature which identifies major weaknesses of such randomized studies, thus refuting claims by school choice advocates that there is a consensus that vouchers for private schools lead to higher academic achievement. These weaknesses relate to: first, problems in properly accounting for selection arising from likely differences in the composition between treated and control groups ${ }^{1}$, as such studies mainly account for observables; and second, inability to account for peer group effects at the school). The other, more recent strand of literature (in which this study belongs), employs large datasets and suitable methodological approaches (multilevel modelling, IV regression, or other techniques) to account for both observables and selection; the findings vary, but more often than not cast doubt on the existence of a positive private school effect and often point to a negative effect (see section 2 for a review).

The fact that existing studies tend to be single country studies or for a particular region/ group (mostly for the OECD group) and vary in their methodology and year, motivates this study. I use PISA 2012 - Mathematics ${ }^{2}$ and a methodologically consistent framework to derive bias-adjusted estimates after accounting for selection on unobservables in 40 countries (from Europe, North America, Oceania, Middle East, South America and East Asia), in which the size of the private sector is nontrivial. The findings generalize certain country-specific and regional findings mentioned in this section and suggest that a robust private school advantage is not frequently observed.

Section 2 provides a non-exhaustive summary of the literature. Section 3 describes the methodology and data used, while section 4 presents and discusses the findings.

\section{Literature review}

Donkers and Robert (2008) used earlier data (PISA 2000) to compare the effectiveness of private and public schools for 15-year olds in 19 OECD countries. They used multi-level analysis, but they did not explicitly account for unobserved confounding factors. They find that private government-subsidized schools seem to be more effective than comparable public schools and attribute this to better school

\footnotetext{
${ }^{1}$ The fact that parents apply for a voucher on behalf of their child may be associated with unobservable qualities (such a motivation, value placed on education, etc.).

${ }^{2}$ Mathematics achievement is considered a better indicator of school effects because it is thought to be less influenced by family background and home effects than other subjects (Bryk et al., 1993. Heyneman, 2005).
} 
climate in private schools; however, independent schools were found to be less effective than comparable public schools.

Vandenberghe and Robin (2004) attempted to estimate the effect of private vs. public education on pupils' achievement using the 2000 OECD PISA survey, taking into account the potential bias due to the existence of unobserved confounding factors. They used three methods: IV regression, Heckman's 2-stage approach and Propensity Score Matching and compared the estimates. Overall, they find that private education does not generate systematic benefits. However, they found significant differences in results between parametric and non-parametric estimators. Using different methods is expected to result in different estimates, as each method has its own weaknesses.

The literature on developing countries also stresses the presence of heterogeneity in findings and the difficulties associated with ascertaining whether any private school advantage found can be fully ascribed to private schools. Day-Ashley et al. (2014) ${ }^{3}$ reviewed 21 studies (mostly of medium quality and only three of high quality) on six developing countries, the majority of them for India. They find only moderate evidence supporting the assumption that private school pupils achieve better learning outcomes than pupils in the public school system.

Evidence on Latin American countries can be found in Somers, McEwan and Willms (2004) and McEwan (2000). Somers, McEwan and Willms $(2004)^{4}$ questioned the supposition that private schools are relatively more effective than public schools at improving student outcomes in Latin American countries using UNESCO data for 10 countries and a multilevel approach. They find that private-public differences in achievement are only partly accounted for by better socioeconomic status of private school students and much more by differing peer-group characteristics. After accounting for peer group characteristics, they find that the average private school effect is near zero, with some variance around the mean. Furthermore, they consider this an upper bound effect, since selection may be biasing the estimates in favour of private schools. Studies which employ empirical strategies which use selection on observables to assess the bias arising from selection on unobservables to account for selection bias (as is this study) are increasingly coming to light. Most of these studies examined the effect of Catholic school attendance on student outcomes (see Altonji, Elder and Taber, 2005; Cardak and Vecci, 2013; Elder and Jepsen, 2014). Their findings point to private schools performing no better than public schools (or even worse).

Recent emerging large scale evidence from the US, also casts doubt on existing beliefs that private schools perform better. The book: The Public School Advantage by Lubienski and Lubienski (2013) is one of the most comprehensive studies of private vs. public school performance in mathematics, utilizing data on test scores from more than 300,000 students and more than 15,000 schools. They find that after controlling for student characteristics, student socioeconomic background and school demographic factors, the private school advantage disappears and often becomes negative.

\footnotetext{
${ }^{3}$ See also Mcloughlin (2013).

${ }^{4}$ See also McEwan (2000).
} 


\section{Data and Methodology}

\subsection{Data}

The PISA 2012 surveys were conducted in 34 OECD countries and 31 partner countries/economies focusing on mathematics, intending to measure what 15-year old students in grade 7 or higher can do with what they learn at school. They contain information and simple indices on student, family background, school and teacher characteristics, as well as information on occupational status and educational level of parents, immigration and language background, indices of engagement with and at school, student drive and motivation, mathematics self-beliefs and various indices of disposition towards mathematics, disciplinary climate at school and teacher-student relations. School level variables and indices contain information on school and class size, student-teacher ratio, school type, availability of computers, quality of teaching staff, ability grouping, use of assessments and school responsibility for curriculum and assessment. School level scale indices contain information on teacher shortages, quality of school resources and infrastructure, teacher and student behaviour and teacher morale.

The survey also contains the constructed Economic, Social and Cultural Status index (ESCS), which is derived from three other indices: (a) highest occupational status of parent, (b) highest educational level of parents in years of education and (c) home possessions. The index of home possessions incorporates all items of the indices on household wealth; household cultural possessions; and books at home. The ESCS index was derived using principal component analysis of standardized variables (OECD mean of zero and standard deviation of one), taking the factor scores of the first principal component as the measure of the ESCS index.

Schools are classified as either public or private, according to whether the ultimate decision maker is a private entity or a public one. This is combined with information on the percentage of total funding which comes from government sources. The generated index of school type allows for the identification of three categories: (1) government-independent private schools, controlled by a non-government organization or with a governing board not selected by a government agency, that receive less than $50 \%$ of their core funding from government agencies, (2) government-dependent private schools, controlled by a non-government organization or with a governing board not selected by a government agency that receive more than $50 \%$ of their core funding from government agencies and (3) public schools controlled and managed by a public education authority or agency.

Table A1 in the Appendix contains information on size of public school sector, proportion of government-dependent vs. private-independent private schools and proportion of schools with a positive peer group index by school type (index of Economic, Social and Cultural Status at the school level), for the 40 countries in this study in which private schools account for at least 3\%, but not exceeding $90 \%$ of all schools. Over all countries, private schools account for nearly a quarter of all 
schools $^{5}$, but there is heterogeneity both between and within groups of countries. In European countries private schools are predominantly government-dependent; the opposite is the case in other areas of the world, especially in the Middle East where almost all private schools are independent. Across all countries, about half of all private schools are government-dependent.

As expected, private schools, especially independent schools have better peer groups compared to public schools. Differences are particularly severe in Latin American countries, while the opposite is the case in East Asian countries, in which peer groups in independent and public schools are much more similar.

\subsection{Methodology}

In the first stage of the investigation I use multilevel analysis - the methodology of choice in assessing school affect differences and handling the nested structure of PISA data. Subsequently, I investigate the effect of remaining selection on unobservables. This framework allows bounding of the estimated private school effect between two values: the base coefficient estimates (such as the fixed coefficients from the mixed effects estimation) and the bias-corrected estimates after accounting for remaining selection (assuming that selection on unobservables is proportional to selection on observables).

\subsubsection{A multilevel model of attainment with random school effects}

Student achievement scores are associated to a variety of student, family, school and other characteristics. One can distinguish school level variation due to various school level (observed) characteristics - such as sector, school resources location, etc., from residual (unobserved) variation between schools. The second can be seen as being associated with differences in school quality (Snijders \& Bosker, 1999; Hanushek \& Rivkin, 2010).

The model which takes into account the hierarchical structure of the data and the estimation of random intercepts associated with a student $i$ belonging to school $j$ is:

$$
Y_{i j}=X_{i j} \beta+S_{j} \gamma+u_{j}+\varepsilon_{i j}
$$

where $Y_{i j}$ is the outcome (achievement score) of student $\mathrm{i}$ in school $\mathrm{j}, \mathrm{X}_{\mathrm{ij}}$ are the individual characteristics identified in the literature as close determinants of school performance and $\mathrm{Sj}$ are the characteristics (resources) of school $\mathrm{j}$ shared by all students attending school $j$. The random component $u_{j}$ is an estimate of the systematic effect of school $\mathrm{j}$ on scores, over and above the effect of the observed school related covariates $(\mathrm{S} j)$ and $\varepsilon_{\mathrm{ij}}$ is a student level residual. The school type variables (privatedependent, independent and pubic) which are part of the vector $\mathrm{S}$, are the focus of interest.

\footnotetext{
${ }^{5}$ This is higher than the $18 \%$ of private schools in PISA 2012 , because countries with only a small proportion of private schools are excluded from this study.
} 
When students are clustered in groups, such as schools, randomly selected students in the same school are expected to be more similar compared to students in another school; consequently, we expect test scores to be more similar than scores in a different school, since they share features of the particular school. One needs, therefore, to take into account clustering; otherwise the standard errors of regression coefficients will be underestimated (especially of predictors measured at the group level such as whether the school is private vs. public).

One reason for using multilevel modelling with random effects is to obtain correct standard errors; an additional reason is to estimate and assess the remaining (residual) between school variation after accounting for observed school level variation. Remaining between school variation (variation of average scores in different schools) can be substantially different between countries.

\subsubsection{Assessing additional selection}

The idea of obtaining information about selection on unobservables from observing coefficient movements of the variable of interest using sensitivity analysis, can be found in earlier literature (Rosenbaum and Rubin,1983; Manski, 2003; Imbens, 2003) and more recently in Altonji et al. (2005; 2008). Altonji et al. (2005) formalized the idea of equal selection (selection on unobservables the same as selection on the observables) and outlined the conditions required. Given an outcome (Y), a treatment (T), a set of observables (X) and a full index of determinants of the outcome (W), it requires that the part of the outcome that is related to the observables as well as the part of the outcome related to the unobservables have the same relationship with the treatment. This assumption, while strong, is weaker than the standard assumption that $\mathrm{X}$ is orthogonal to the error term. Additional requirements for equal selection are: First, the elements in $\mathrm{X}$ is a random selection from the complete set (W), which determines the outcome ${ }^{6}$; and second, the number of elements (determinants) in $\mathrm{X}$ and $\mathrm{W}$ are large, with no element dominating the distribution of the treatment or the outcome.

Oster (2013) built on Altonji et al. (2005) and related intuitive methodologies and further connected the theory to empirical work. The additional insight is recognizing that coefficient stability is not informative on its own, but it needs to be combined with information on R-squared movements; in the presence of multiple controls, using additional information (and a general estimator) is important, as it is possible to observe stable coefficients and large R-squared movements even when large biases exist. This methodology allows for more flexibility in examining the robustness of estimated effects under selection, the estimation of selection bias and bias-adjusted effects.

In the simple case of a treatment and a single observable, consider the linear equation:

$$
\mathrm{Y}=\beta \mathrm{T}+\gamma_{1} w_{1}^{0}+\mathrm{W}_{2}+\epsilon
$$

\footnotetext{
${ }^{6}$ As noted in Altonji et al. (2005) this assumption is not to be taken literally, since it is more likely that the relationship between the treatment and observables is stronger than the relationship between the treatment and unobservables.
} 
where $T$ is the treatment of interest with coefficient $\beta$, index $W_{1}=\gamma_{1} w_{1}^{0}$ is the observed control with coefficient $\gamma_{1}, \mathrm{~W}_{2}$ is a vector (linear combination) of unobserved controls multiplied by their true coefficients and the error, $\epsilon$, is orthogonal to $\mathrm{T}, \mathrm{W}_{1}$ and $\mathrm{W}_{2}$. Under equal selection (selection on unobservables as important as selection on observables), consider the regression of $\mathrm{Y}$ on $\mathrm{T}$ with a sample coefficient $\beta^{\circ}$ and R-squared $R^{\circ}$, and the regression of $\mathrm{Y}$ on $\mathrm{T}$ and $w_{1}^{0}$ with coefficient $\tilde{\beta}$ and Rsquared $\widetilde{\mathrm{R}}$. Furthermore, define $\mathrm{R}_{\max }$ as the $\mathrm{R}$-squared that would have been obtained had we been able to regress $\mathrm{Y}$ on $\mathrm{T}, w_{1}^{0}$ and $\mathrm{W}_{2}$. Then, using standard omitted variable bias formulas, it can be shown that under the equal selection assumption, the ratio of the change in coefficients is equal to the ratio of the change in $\mathrm{R}$-squared.

Oster (2013) derived a general estimator under proportional selection (selection on unobservables is proportional to selection on observables) with a coefficient of proportionality $\delta$ and multiple observables. As discussed in Altonjie et al. (2002), the value $\delta=1$ is a suitable bounding value. In applications, one can either calculate the value of $\delta$ so that $\beta=0$ (degree of selection necessary to explain away the estimate), or calculate the bias-adjusted $\beta$ while assuming that $\delta=1$. In our case, the objective is to select reasonable bounding assumptions on $\mathrm{R}_{\max }$ and $\delta$ to generate bounds for the treatment effect. The particulars of the application, along with intuition can help in selecting an $\mathrm{R}_{\max }$ between $\widetilde{\mathrm{R}}$ and 1 , and $\delta$ values which are bounded below at 0 and above at some arbitrary $\delta$.

In this study, having used a broad set of individual, socioeconomic, attitudinal and school measures which constitute a subset of the complete set (W) which determines the outcome, suggests that the observables could provide a useful guide to role of unobservables. As is the case with other published studies using the same approach, it is acknowledged that the estimates are unlikely to uncover the true private school effect; rather, the objective is to derive estimates of lower and upper bounds of this effect across countries.

\section{Results and discussion}

\subsection{Raw score differences}

Tables $1 \mathrm{a}$ and $1 \mathrm{~b}$ report results separately for the private-dependent vs. public school and the private-independent vs. public school comparisons. A country enters into the table when the size of the private school subsector is not trivial (at least three schools and 100 students in the subsector). In total, 32 countries are reviewed in Table 1a and 31 in Table $1 \mathrm{~b}$ (40 countries in total). Countries with very small private-independent school subsector which were excluded from the analysis are: Czech Republic, Germany, The Netherlands and Slovakia; Belgium (with 3 schools and 100 students), was included. Countries with small private-dependent school subsector excluded from the analysis are: Greece, the USA, Jordan and Qatar. Furthermore, schools with less than 10 students participating in the survey were excluded, as including them can affect the reliability of estimates on the effectiveness of private schools. 
As in many other studies using PISA data I use the average of the five mathematics plausible values in the data. ${ }^{7}$ The mean raw score difference between both types of private schools and public schools (reported in column 1 of both tables) is, with very few exceptions, heavily in favour of private schools, especially in Latin America and the Middle East; however, in East Asia the opposite is the case, especially for privatedependent schools. Across all countries, the mean differential is much larger when private-independent schools are compared to public schools compared to when private-independent schools are compared to public schools. The mean gaps are much larger in Latin America and Middle East, compared to East Asia.

\subsection{Estimation of private school effects}

The dependent variable is the standardized mathematics score, to facilitate comparison between countries. The list of controls includes the following student and family characteristics: Age, gender, preschool attendance, being first generation immigrant, being second generation immigrant, community size, family structure, Economic, Social and Cultural Status index (ESCS), out of school study time, index of parental pressure, and index of perseverance. It also includes the following school and institutional characteristics: Private school sub-type (private-dependent or independent), number of schools in the community, attending same sex schools, class size, school size, proportion of certified teachers, ability grouping at school, school autonomy, teacher shortages, as well as indices on student climate and school educational resources. Finally, the model also controls for peer group quality at the school level (derived from the ESCS index); estimates were also derived excluding peer group quality controls, to evaluate their contribution to the private school effect.

Column 2 in Table 1a presents the fixed coefficients of private-dependent school attendance (vs., public school attendance) from mixed-effects regressions. In threequarters of the countries public schools perform equally well as private-dependent schools. In four countries (Belgium, Canada, Argentina and Brazil) a significant private school effect is found. In seven countries (Czech Republic, Germany, UAE, Costa-Rica, Mexico, Taiwan and Thailand) the opposite is the case. On average, over all OECD countries, the effect of attending private-dependent schools is indistinguishable to that of attending public schools. On the other hand, in Latin American and East Asian countries a moderate in magnitude effect in favour of public schools is found.

Column 2 of Table $1 \mathrm{~b}$ presents the fixed coefficients of private-independent school attendance from mixed-effects regressions. In the majority of countries independent schools and public schools perfume equally well. An independent school advantage is, however, found in several countries: Belgium, Greece, Canada, Ireland, New Zealand, Qatar, Brazil and Indonesia. In six countries (Switzerland, Australia, Costa Rica, Japan, Taiwan and Thailand) a public school advantage is found.

Column 3 of Tables 1a and $1 \mathrm{~b}$ presents the estimated coefficients from multiple linear regressions with standard errors clustered at the school level and using the same

\footnotetext{
${ }^{7}$ For comparison, I also used the specialized Stata program $p v$ (authored by Kevin Macdonald) for application in the education assessment literature, which estimates statistics when there are multiple plausible values. There were no substantial differences in estimates that would affect the conclusions about the nature of the private-public school differentials.
} 
model specification. A casual comparison of columns 2 and 3 reveals that the two sets of coefficients are very similar in almost all countries and allow for the same conclusion on the effectiveness of private schools.

Table 1a: Estimated effects on the standardized Mathematics PISA score - Private-dependent vs.

Public schools

\begin{tabular}{|c|c|c|c|c|c|}
\hline \multirow{2}{*}{$\begin{array}{l}\text { Country } \\
\text { OECD }\end{array}$} & \multirow[t]{2}{*}{$\begin{array}{c}\text { (1) } \\
\text { Raw score diff: } \\
\text { Private - Public } \\
\end{array}$} & \multirow[t]{2}{*}{$\begin{array}{c}(2) \\
\text { Mixed-effects regression } \\
\text { Fixed coefficients } \\
\end{array}$} & \multirow[t]{2}{*}{$\begin{array}{c}(3) \\
\begin{array}{c}\text { Multiple regression: } \\
\text { coefficients }\end{array} \\
\end{array}$} & \multicolumn{2}{|c|}{$\begin{array}{c}(4) \\
\text { Bias-adjusted effect }\end{array}$} \\
\hline & & & & $\delta=0.5$ & $\delta=1$ \\
\hline Austria* & $0.517(0.054)$ & $-0.040(0.179)$ & $-0.111(0.154)$ & -0.262 & -0.380 \\
\hline Belgium & $0.547(0.024)$ & $0.212(0.065)$ & $0.233(0.052)$ & 0.154 & 0.074 \\
\hline Czech Republic & $-0.023(0.052)$ & $-0.262(0.110)$ & $-0.244(0.101)$ & -0.184 & -0.227 \\
\hline Denmark & $0.288(0.028)$ & $-0.022(0.071)$ & $0.026(0.070)$ & -0.031 & -0.106 \\
\hline Finland & $0.237(0.064)$ & $0.070(0.075)$ & $0.066(0.073)$ & 0.023 & 0.007 \\
\hline France* & $0.341(0.037)$ & $-0.121(0.120)$ & $-0.079(0.096)$ & -0.178 & -0.283 \\
\hline Germany & $0.367(0.060)$ & $-0.460(0.174)$ & $-0.279(0.143)$ & -0.450 & -0.637 \\
\hline Hungary & $0.174(0.044)$ & $-0.102(0.112)$ & $-0.090(0.108)$ & -0.118 & -0.187 \\
\hline Ireland & $0.275(0.048)$ & $0.073(0.055)$ & $0.067(0.048)$ & 0.067 & 0.068 \\
\hline Italy & $-0.409(0.052)$ & $-0.091(0.127)$ & $-0.133(0.129)$ & -0.088 & -0.042 \\
\hline Netherlands & $-0.047(0.033)$ & $0.059(0.143)$ & $0.126(0.097)$ & 0.184 & 0.242 \\
\hline Poland & $0.566(0.092)$ & $0.022(0.176)$ & $0.184(0.181)$ & 0.097 & 0.003 \\
\hline Portugal & $0.381(0.051)$ & $-0.018(0.134)$ & $-0.198(0.109)$ & -0.347 & -0.516 \\
\hline Slovakia & $0.427(0.058)$ & $0.044(0.141)$ & $0.047(0.118)$ & -0.081 & -0.208 \\
\hline Spain & $0.406(0.022)$ & $0.051(0.056)$ & $0.036(0.053)$ & -0.042 & -0.126 \\
\hline Sweden & $0.169(0.043)$ & $0.122(0.073)$ & $0.082(0.065)$ & 0.061 & 0.039 \\
\hline Switzerland & $0.390(0.102)$ & $0.350(0.342)$ & $0.024(0.312)$ & -0.104 & -0.247 \\
\hline United Kingdom & $0.128(0.033)$ & $0.027(0.071)$ & $0.025(0.063)$ & -0.021 & -0.068 \\
\hline Canada & $0.664(0.037)$ & $0.360(0.098)$ & $0.345(0.092)$ & 0.291 & 0.236 \\
\hline Australia & $0.731(0.026)$ & $0.046(0.092)$ & $-0.051(0.077)$ & -0.260 & -0.512 \\
\hline Mean & 0.305 & 0.016 & 0.004 & -0.064 & -0.144 \\
\hline \multicolumn{6}{|l|}{ MENA } \\
\hline UAE & $0.694(0.033)$ & $-0.192(0.088)$ & $-0.125(0.085)$ & -0.219 & -0.320 \\
\hline \multicolumn{6}{|l|}{ Latin America } \\
\hline Argentina & $0.800(0.030)$ & $0.267(0.102)$ & $0.333(0.086)$ & 0.206 & 0.065 \\
\hline Brazil & $1.04(0.061)$ & $0.328(0.164)$ & $0.305(0.140)$ & 0.085 & -0.176 \\
\hline Chile & $0.396(0.025)$ & $0.014(0.135)$ & $-0.016(0.089)$ & 0.055 & 0.129 \\
\hline Colombia & $0.148(0.057)$ & $-0.217(0.148)$ & $-0.124(0.134)$ & -0.177 & -0.231 \\
\hline Costa Rica & $0.875(0.061)$ & $-1.06(0.272)$ & $-0.583(0.299)$ & -0.890 & -1.25 \\
\hline Mexico & $0.431(0.055)$ & $-0.381(0.144)$ & $-0.279(0.142)$ & -0.431 & -0.605 \\
\hline Peru & $0.744(0.067)$ & $-0.031(0.150)$ & $0.145(0.135)$ & 0.032 & -0.090 \\
\hline Mean & 0.633 & -0.154 & -0.031 & -0.160 & -0.308 \\
\hline \multicolumn{6}{|l|}{ East Asia } \\
\hline Indonesia & $-0.524(0.032)$ & $0.179(0.190)$ & $0.013(0.182)$ & 0.175 & 0.361 \\
\hline Korea & $-0.067(0.031)$ & $0.091(0.102)$ & $-0.007(0.073)$ & 0.050 & 0.110 \\
\hline Taiwan & $-0.997(0.046)$ & $-0.519(0.156)$ & $-0.601(0.097)$ & -0.542 & -0.480 \\
\hline Thailand & $-0.413(0.033)$ & $-0.430(0.140)$ & $-0.342(0.073)$ & -0.295 & -0.247 \\
\hline Mean & -0.500 & -0.170 & -0.234 & -0.153 & -0.064 \\
\hline Overall mean & 0.289 & -0.051 & -0.038 & -0.101 & -0.175 \\
\hline
\end{tabular}

Note: Clustered standard errors in parentheses in column 3.

* For Austria and France there is no information for separating private schools in dependent and independent. 
Table 1b: Estimated effects on the standardized Mathematics PISA score - Private-Independent vs. Public schools

\begin{tabular}{|c|c|c|c|c|c|}
\hline \multirow{2}{*}{$\begin{array}{l}\text { Country } \\
O E C D \\
\end{array}$} & \multirow[t]{2}{*}{$\begin{array}{l}\quad(1) \\
\text { Raw score diff: } \\
\text { Private - Public } \\
\end{array}$} & \multirow[t]{2}{*}{$\begin{array}{c}(2) \\
\text { Mixed-effects regression: } \\
\text { Fixed coefficients } \\
\end{array}$} & \multirow[t]{2}{*}{$\begin{array}{c}(3) \\
\text { Multiple regression: } \\
\text { Coefficients } \\
\end{array}$} & \multicolumn{2}{|c|}{$\begin{array}{c}(4) \\
\text { Bias-adjusted effect: }\end{array}$} \\
\hline & & & & $\underline{\delta=0.5}$ & $\underline{\delta=1}$ \\
\hline Belgium & $1.63(0.057)$ & $0.615(0.100)$ & $0.597(0.086)$ & 0.440 & 0.270 \\
\hline Denmark & $0.389(0.057)$ & $0.057(0.126)$ & $0.117(0.099)$ & 0.048 & -0.018 \\
\hline Greece & $1.29(0.077)$ & $0.516(0.167)$ & $0.812(0.123)$ & 0.699 & 0.576 \\
\hline Ireland & $0.882(0.085)$ & $0.287(0.105)$ & $0.223(0.108)$ & 0.095 & -0.049 \\
\hline Italy & $0.334(0.059)$ & $0.000(0.154)$ & $-0.130(0.129)$ & -0.206 & -0.287 \\
\hline Poland & $0.742(0.089)$ & $-0.019(0.252)$ & $0.060(0.185)$ & -0.119 & -0.326 \\
\hline Portugal & $1.10(0.055)$ & $-0.051(0.149)$ & $-0.040(0.110)$ & -0.348 & -0.712 \\
\hline Spain & $0.607(0.033)$ & $0.070(0.085)$ & $0.036(0.079)$ & -0.046 & -0.133 \\
\hline Switzerland & $-0.300(0.058)$ & $-0.543(0.137)$ & $-0.763(0.150)$ & -0.869 & -0.938 \\
\hline United Kingdom & $0.956(0.051)$ & $0.238(0.152)$ & $0.266(0.133)$ & 0.116 & -0.056 \\
\hline Canada & $0.656(0.052)$ & $0.268(0.105)$ & $0.249(0.120)$ & 0.127 & -0.012 \\
\hline USA & $0.030(0.050)$ & $-0.162(0.118)$ & $-0.506(0.109)$ & -0.632 & -0.764 \\
\hline Australia & $0.240(0.020)$ & $-0.113(0.051)$ & $-0.128(0.051)$ & -0.206 & -0.290 \\
\hline New Zealand & $0.923(0.065)$ & $0.301(0.114)$ & $0.241(0.097)$ & 0.075 & -0.114 \\
\hline Mean & 0.679 & 0.105 & $\mathbf{0 . 0 7 3}$ & -0.059 & -0.204 \\
\hline \multicolumn{6}{|l|}{ MENA } \\
\hline Jordan & $0.904(0.046)$ & $0.238(0.136)$ & $0.475(0.114)$ & 0.343 & 0.193 \\
\hline Qatar & $1.09(0.018)$ & $0.256(0.098)$ & $0.312(0.100)$ & -0.079 & -0.601 \\
\hline UAE & $0.750(0.023)$ & $-0.156(0.089)$ & $-0.164(0.075)$ & -0.373 & -0.619 \\
\hline Mean & 0.915 & 0.113 & 0.208 & -0.036 & -0.342 \\
\hline \multicolumn{6}{|l|}{ Latin America } \\
\hline Argentina & $0.791(0.053)$ & $0.160(0.161)$ & $0.283(0.167)$ & 0.153 & 0.010 \\
\hline Brazil & $1.22(0.034)$ & $0.401(0.158)$ & $0.308(0.136)$ & -0.042 & -0.501 \\
\hline Chile & $1.33(0.030)$ & $0.235(0.173)$ & $0.155(0.139)$ & -0.478 & -1.46 \\
\hline Colombia & $1.01(0.052)$ & $-0.059(0.188)$ & $0.165(0.161)$ & -0.127 & -0.495 \\
\hline Costa Rica & $1.30(0.063)$ & $-0.861(0.298)$ & $-0.189(0.327)$ & -0.611 & -1.14 \\
\hline Mexico & $0.618(0.024)$ & $-0.154(0.116)$ & $-0.193(0.094)$ & -0.386 & -0.616 \\
\hline Peru & $0.967(0.040)$ & $0.101(0.149)$ & $0.147(0.135)$ & -0.081 & -0.353 \\
\hline Uruguay & $1.18(0.033)$ & $0.046(0.203)$ & $0.141(0.248)$ & -0.246 & -0.754 \\
\hline Mean & 1.05 & -0.016 & 0.102 & -0.227 & -0.664 \\
\hline \multicolumn{6}{|l|}{ East Asia } \\
\hline Indonesia & $0.273(0.040)$ & $0.534(0.182)$ & $0.353(0.186)$ & 0.369 & 0.386 \\
\hline Japan & $0.050(0.029)$ & $-0.628(0.206)$ & $-0.613(0.076)$ & -0.806 & -0.805 \\
\hline Korea & $0.650(0.037)$ & $0.064(0.188)$ & $0.152(0.088)$ & 0.005 & -0.163 \\
\hline Taiwan & $-0.476(0.028)$ & $-0.545(0.097)$ & $-0.623(0.083)$ & -0.689 & -0.756 \\
\hline Thailand & $-0.390(0.063)$ & $-0.491(0.229)$ & $-0.456(0.139)$ & -0.438 & -0.420 \\
\hline Vietnam & $-0.194(0.049)$ & $-0.451(0.284)$ & $-0.756(0.170)$ & -0.844 & -0.938 \\
\hline Mean & -0.015 & -0.253 & -0.324 & -0.401 & -0.449 \\
\hline Overall mean & 0.664 & 0.005 & 0.017 & -0.166 & -0.383 \\
\hline
\end{tabular}

Note: Clustered standard errors in parentheses in column 3.

\subsection{The importance of peer groups}

The contribution of school peer group effects was evaluated by comparing multiple regressions without and with peer group controls. This contribution varies between country groups. Table A2 in the Appendix summarizes the controlled effects without and with peer group controls by country grouping; the effects with peer controls are from column 3 in tables $1 \mathrm{a}$ and $1 \mathrm{~b}$. Accounting for peer effects is particularly 
important in deriving the independent school effect, as without such peer group controls the average effect would have been about 0.188 of a standard deviation in favour of independent schools, compared to approximately zero with such controls. Peer effects are much more important in Latin American countries. On the other hand, in East Asian countries peer effects contribute very little in explaining the independent school effect.

When comparing private-dependent schools to public schools, peer effects are relatively less important, as dependent schools are not very different from public schools in peer group composition; however, in the Latin American group of countries such effects are still important.

\subsection{Bias-corrected estimates of private school effects}

Robustness checking in the presence of selection was conducted using assumptions on the value of $\mathrm{R}_{\max }$ and $\delta$, in order to obtain bounding values of $\beta$. Such bounding values can then be compared to the controlled estimates given in column 3 of Tables $1 \mathrm{a}$ and $1 \mathrm{~b}$ (i.e., assuming $\delta=0, \mathrm{R}=\widetilde{\mathrm{R}}, \beta=\widetilde{\beta}$ ). It is reasonable to assume an $\mathrm{R}_{\max }<1$, considering the possibility of measurement error in the dependent variable, $\mathrm{Y}$, or variation in $\mathrm{Y}$ which is not related to $\mathrm{X}$, i.e., variation arising from choices made after $\mathrm{X}$ is determined.

I use the value of $R_{\max }=1.5 \widetilde{R}$ without explicitly considering higher values, since any higher value would simply reinforce the conclusions of this study. With respect to the extent of selection on unobservables in relation to observables, I use two alternative values: $\delta=0.5$ (unobservables are half as important as observables) and the upper bound value of $\delta=1$ (equal selection).

Estimation of standard errors is not possible with the program used ${ }^{8}$. An indication of statistical significance of the bias-corrected estimates can be derived by inspecting the statistical significance of base estimates and comparing the magnitude of the corrected vs. the base coefficients.

Column 4 in Table 1a reports the bias-corrected estimates ${ }^{9}$ of the effect of attending private-dependent schools relative to public schools. With few exceptions, the biascorrected estimates are lower than the controlled estimates of the private school effect; over all countries, the estimated effect is negative but small. In the great majority of countries, either no significant effect or a public school advantage is found. However, in a small number of countries private-dependent schools perform better than public schools. These are Canada, Indonesia (under equal selection), and possibly Netherlands and Argentina (under moderate amount of selection). Column 4 in Table $1 \mathrm{~b}$ reports the corresponding estimates of the bias-corrected effect for attending independent schools. Even assuming moderate selection, in approximately half of the countries a public school advantage is found, while in several other public schools perform equally well as independent schools. Again, in a very small number of countries the independent school advantage remains robust. These are Belgium, Greece and Indonesia, with some evidence that this may be the case for Jordan.

\footnotetext{
${ }^{8}$ The absence of standard errors would be more of a problem in a single country study, but less so for the objectives of the present study.

${ }^{9}$ The Stata program PSACALC provided by Emily Oster was used.
} 
Tables $2 \mathrm{a}, 2 \mathrm{~b}$ and $2 \mathrm{c}$ classify by country the outcome of the comparison between school types (private school advantage, public school advantage and equal effectiveness), after correcting for omitted variable bias. I distinguish between conclusions which apply for any amount of selection and conclusions which apply under the assumption of moderate or equal selection. Under the assumption that the bias due to selection on unobservables is not large, no difference in effectiveness is found in the majority of countries when comparing private-dependent schools to public schools; however, when comparing independent schools to public schools, a public school advantage is nearly as prevalent as equal effectiveness.

Table 2a: Private school advantage, by country

\begin{tabular}{|c|c|c|}
\hline Country & Private-dependent vs. Public & Independent vs. Public \\
\hline Belgium & $\sqrt{(\text { a) }}$ & $\sqrt{ }$ \\
\hline Greece & & $\sqrt{ }$ \\
\hline Netherlands & $\sqrt{(b)}$ & \\
\hline Canada & $\sqrt{ }$ & \\
\hline Jordan & & $\sqrt{(a)}$ \\
\hline Argentina & $\sqrt{(a)}$ & \\
\hline Indonesia & $\sqrt{(b)}$ & $\sqrt{ }$ \\
\hline
\end{tabular}

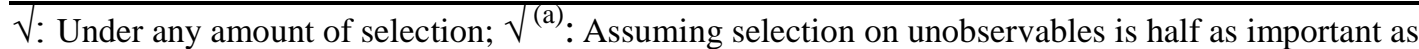
selection on observables; $\sqrt{ }^{(b)}$ : Assuming equal selection.

Table 2b: Public school advantage, by country

\begin{tabular}{|c|c|c|}
\hline Country & Private-dependent vs. Public & Independent vs. Public \\
\hline Austria & $\sqrt{(\mathrm{b})}$ & \\
\hline Czech Republic & $\sqrt{(b)}$ & \\
\hline France & $\sqrt{(b)}$ & \\
\hline Germany & $\sqrt{ }$ & \\
\hline Portugal & $\sqrt{ }$ & $\sqrt{ }$ \\
\hline Spain & $\sqrt{(b)}$ & \\
\hline Switzerland & & $\sqrt{ }$ \\
\hline USA & & $\sqrt{ }$ \\
\hline Australia & $\sqrt{ }$ & $\sqrt{ }$ \\
\hline UAE & $\sqrt{ }$ & $\sqrt{ }$ \\
\hline Qatar & & $\sqrt{(b)}$ \\
\hline Brazil & & $\sqrt{(b)}$ \\
\hline Chile & & $\sqrt{ }$ \\
\hline Colombia & & $\sqrt{(b)}$ \\
\hline Costa Rica & $\sqrt{ }$ & $\sqrt{ }$ \\
\hline Mexico & $\sqrt{ }$ & $\sqrt{ }$ \\
\hline Peru & & $\sqrt{(b)}$ \\
\hline Uruguay & & $\sqrt{(b)}$ \\
\hline Japan & & $\sqrt{ }$ \\
\hline Taiwan & $\sqrt{ }$ & $\sqrt{ }$ \\
\hline Thailand & $\sqrt{ }$ & $\sqrt{ }$ \\
\hline Vietnam & & $\sqrt{ }$ \\
\hline
\end{tabular}


Table 2c: Private and public schools equally effective, by country

\begin{tabular}{|c|c|c|}
\hline Country & Private-dependent vs. Public & Independent vs. Public \\
\hline Austria & $\sqrt{ }^{(\mathrm{a})}$ & \\
\hline Czech Republic & $\sqrt{(a)}$ & \\
\hline France & $\sqrt{(\mathrm{a})}$ & \\
\hline Denmark & $\sqrt{ }$ & $\sqrt{ }$ \\
\hline Finland & $\sqrt{ }$ & \\
\hline Hungary & $\sqrt{ }$ & \\
\hline Ireland & $\sqrt{ }$ & $\sqrt{ }$ \\
\hline Italy & $\sqrt{ }$ & $\sqrt{ }$ \\
\hline Netherlands & $\sqrt{(a)}^{(a)}$ & \\
\hline Poland & $\sqrt{ }$ & $\sqrt{ }$ \\
\hline Slovakia & $\sqrt{ }$ & \\
\hline Spain & $\sqrt{(a)}$ & $\sqrt{ }$ \\
\hline Sweden & $\sqrt{ }$ & \\
\hline Switzerland & $\sqrt{ }$ & \\
\hline Canada & & $\sqrt{1}$ \\
\hline UK & $\sqrt{ }$ & $\sqrt{ }$ \\
\hline New Zealand & & $\sqrt{ }$ \\
\hline Argentina & . & $\sqrt{ }$ \\
\hline Qatar & & $\sqrt{(a)}$ \\
\hline Brazil & $\sqrt{ }$ & $\sqrt{(\mathrm{a})}$ \\
\hline Chile & $\sqrt{ }$ & \\
\hline Colombia & $\sqrt{ }$ & $\sqrt{(\text { a) }}$ \\
\hline Peru & $\sqrt{ }$ & $\sqrt{(\text { a) }}$ \\
\hline Uruguay & & $\sqrt{(\mathrm{a})}$ \\
\hline Indonesia & $\sqrt{(a)}$ & \\
\hline Korea & $\sqrt{ }$ & $\sqrt{ }$ \\
\hline
\end{tabular}

\subsection{Further discussion and conclusions}

In assessing the effectiveness of private schools from a policy maker's perspective (but not necessarily from parents' perspective), one needs to consider whether any private advantage found (for example in voucher studies), is due to positive spillovers from better peer groups; if this is so, the results of such studies are undermined. As argued in Somers, McEwan and Willms (2004), since the stock of good peers is finite, expanding the private school sector requires enrolling increasingly diverse populations drown from middle and lower income groups, gradually weakening private school effects at the margin.

While there is no ideal methodological approach, this study finds that accounting for both peer effects and selection is necessary when evaluating school effectiveness. This study finds that in OECD, Middle Eastern and Latin American countries, using peer controls eliminates the private-dependent school advantage and severely reduces the estimated independent school advantage, before accounting for selection. On the other hand, accounting for selection in addition to peer effects is particularly important when comparing public to independent schools; this is because the effect unobservables can be substantial in this comparison.

Given the findings in this study along with other emerging evidence, what are possible explanations for the finding that private schools are underperforming compared to public schools? While this question has not been extensively researched 
and can be country dependent, Lubienski and Lubienski (2013) in The Public School Advantage suggest that part of the answer may lie in features of private schools which have been previously praised, such as more autonomy and less regulation. It may be the case that the more regulated public school sector embraces more innovative and effective practices, while independent schools are less prone to reforms, leading to curricular stagnation. More generally, they suggest that public schools tend to apply a more professional model of teaching and learning.

Private schools are here to stay. There are parents who are attracted to certain features of private schools; if school effectiveness is enhanced by spillovers related to peergroup composition, parents would welcome such spillovers as long as their child benefits. However, credible evidence on effectiveness of private vs. public schools needs to be taken into account by policy makers when designing policies on the extent of public funding for private sector provision and on whether such provision is justified. Given the findings of this study, equity considerations should be considered, along with effectiveness and efficiency considerations.

\section{References}

Altonji, J., Elder, T. E. \& Taber, C. (2002) An evaluation of instrumental variable strategies for estimating the effects of Catholic schools. NBER Working Papers 9358, National Bureau of Economic Research, Cambridge, MA.

Altonji, J., Elder, T. E. \& Taber, C. (2005) Selection on observed and unobserved variables: Assessing the effectiveness of Catholic schools. Journal of Political Economy, Vol. 113 (1), 151-184.

Bryk, A.S., Lee, V. E. \& Holland, P. B. (1993) Catholic schools and the common good. Harvard University Press: Cambridge, MA.

Coleman, J. \& Hoffer, T. (1987) Public and private high schools: The impact of communities. New York: Basic Books.

Coleman, J., Hoffer, T. \& Kilgore, S. (1982) High school achievement: Public, Catholic, and private schools compared. New York: Basic Books.

Cardak, B. \& Vecci J. (2013) Catholic school effectiveness in Australia: A reassessment using selection on observed and unobserved variables. Economics of Education Review, Vol. 37(C), 34-45.

Day Ashley, C., Mcloughlin, C., Aslam, M., Engel, J., Wales, J., Rawal,S., Batley, R., Kingdon, G., Nicolai, S. \& Rose, P. (2014) The Role and impact of private schools in developing countries: A rigorous review of the evidence. London: Department for International Development.

Donkers, J. \& Robert P., (2008) Differences in scholastic achievement of public, private government-dependent, and private independent schools: A cross-national analysis. Educational Policy, Vol. 22 (4), 541-577.

Elder, T. \& Jepsen C. (2014) Are Catholic primary schools more effective than public primary schools?. Journal of Urban Economics, Vol. 80 (March), 28-38.

French, R. \& Kingdon, G. (2010) The relative effectiveness of private and government schools in Rural India: Evidence from ASER data. DoQSS Working Paper No. 1003. Institute of Education, University of London. 
Hanushek, E. \& Rivkin, S. (2010) Generalizations about using value-added measures of teacher quality. American Economic Review, 100(2), 267-271.

Heyneman, S. P. (2005) Student background and student achievement: What is the right question? American Journal of Education, 112: 1-9.

Imbens, G. (2003) Sensitivity to Exogeneity assumptions in program evaluation. American Economic Review, Vol. 93 (2), 126-132.

Lubienski, C., Weitzel, P. \&. Lubienski, S. T (2009) Is there a "consensus" on school choice and achievement? Advocacy research and the emerging political economy of knowledge production. Educational Policy Vol. 23 (1), 161-193.

Lubienski, C. \& Lubienski, S. T. (2013) The Public School Advantage. University of Chicago Press, Chicago.

Manski, C. (2003) Partial Identification of Probability Distributions. Springer Series in Statistics.

McEwan, P. J. (2000) Comparing the effectiveness of public and private schools: A review of evidence and interpretations. National Centre for the Study of Privatization in Education Occasional Paper $N^{\circ} 3$, Teachers College, Columbia University.

Mcloughlin, C. (2013) Low-cost private schools: Evidence, approaches and emerging issues. EPS-Peaks, U.K.

Oster, E. (2013) Unobservable selection and coefficient stability: Theory and validation. NBER Working Papers 19054, National Bureau of Economic Research, Cambridge, MA.

OECD (2011) Private schools: Who benefits?. PISA in focus 7, Education Policy, Paris, France.

Rosenbaum, P. \& Rubin, D. (1983) Assessing Sensitivity to an Unobserved Binary Covariate in an Observational Study with Binary Outcome. Journal of the Royal Statistical Society, Series B, Vol. 45 (2), 212-218.

Somers, M. A., McEwan P. J. \& Willms, J. D. (2004) How effective are private schools in Latin America? Comparative Education Review, Vol. 48 (1), 48-69.

Snijders, T. \& Bosker, R. (1999) Multilevel Analysis. London: Sage.

Vandenberghe, V. \& Robin, S. (2004) Evaluating the effectiveness of private education across countries: a comparison of methods."Labour Economics, Vol. 11(4), 487-506. 


\section{Appendix}

Table A1: Summary statistics of variables of interest by country

\begin{tabular}{|c|c|c|c|c|c|}
\hline Country & $\begin{array}{l}(1) \\
\% \text { Private }\end{array}$ & $\begin{array}{c}(2) \\
\text { (\%) Dependent / } \\
\text { Independent schools }\end{array}$ & $\begin{array}{c}(3) \\
\% \text { positive peer index } \\
\text { (Private-dependent) }\end{array}$ & $\begin{array}{c}\text { (4) } \\
\text { \% positive peer index } \\
\text { (Private-independent) }\end{array}$ & $\begin{array}{c}\text { (5) } \\
\% \begin{array}{c}\text { positive peer index } \\
\text { (Public) }\end{array}\end{array}$ \\
\hline \multicolumn{6}{|c|}{ 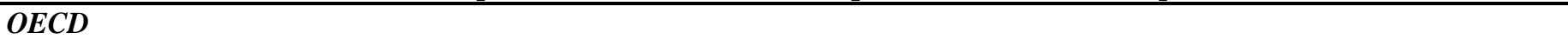 } \\
\hline Austria* & 11.4 & $\mathrm{n} / \mathrm{a}$ & 93.9 & $\mathrm{n} / \mathrm{a}$ & 49.5 \\
\hline Belgium & 70.8 & $98 / 2$ & 68.0 & 100 & 51.5 \\
\hline Czech Republic & 7.8 & $85 / 15$ & 64.7 & 0 & 51.1 \\
\hline Denmark & 16.5 & $86 / 14$ & 82.1 & 97.0 & 72.0 \\
\hline Finland & 5.9 & $100 / 0$ & 87.7 & - & 86.5 \\
\hline France* & 20.1 & $\mathrm{n} / \mathrm{a}$ & 68.7 & $n / a$ & 46.3 \\
\hline Germany & 6.4 & $91 / 9$ & 96.5 & 100 & 55.3 \\
\hline Greece & 5.2 & $29 / 71$ & 100 & 100 & 42.2 \\
\hline Hungary & 15.3 & $100 / 0$ & 45.6 & - & 36.5 \\
\hline Ireland & 60.1 & $92 / 8$ & 68.6 & 95.3 & 53.4 \\
\hline Italy & 4.7 & $66 / 34$ & 33.2 & 87.7 & 46.7 \\
\hline Netherlands & 67.4 & $98 / 2$ & 68.6 & 100 & 75.2 \\
\hline Poland & 8.2 & $60 / 40$ & 80.3 & 100 & 26.2 \\
\hline Portugal & 9.2 & $61 / 39$ & 33.4 & 100 & 16.0 \\
\hline Slovakia & 8.0 & $93 / 7$ & 78.1 & 100 & 33.3 \\
\hline Spain & 38.4 & $86 / 14$ & 60.1 & 84.6 & 18.8 \\
\hline Sweden & 16.6 & $100 / 0$ & 85.0 & - & 77.0 \\
\hline Switzerland & 4.2 & $28 / 72$ & 96.1 & 91.8 & 54.4 \\
\hline United Kingdom & 19.6 & $79 / 21$ & 84.3 & 100 & 69.0 \\
\hline Canada & 8.3 & $52 / 48$ & 85.2 & 100 & 87.0 \\
\hline USA & 8.7 & $10 / 90$ & 100 & 98.9 & 61.1 \\
\hline Australia & 38.9 & $28 / 72$ & 98.5 & 91.5 & 47.5 \\
\hline New Zealand & 6.0 & $0 / 100$ & 45.0 & 98.1 & 51.0 \\
\hline Mean & 19.9 & $68 / 32$ & 74.6 & 81.5 & 52.5 \\
\hline \multicolumn{6}{|l|}{ MENA } \\
\hline Jordan & 11.1 & $4 / 96$ & 0 & 57.5 & 9.0 \\
\hline Qatar & 38.0 & $2 / 98$ & 100 & 92.2 & 76.4 \\
\hline UAE & 57.5 & $27 / 73$ & 91.3 & 88.9 & 45.7 \\
\hline Mean & 35.5 & $11 / 89$ & 63.8 & 79.5 & 43.7 \\
\hline \multicolumn{6}{|l|}{ Latin America } \\
\hline Argentina & 36.5 & $77 / 23$ & 49.1 & 71.3 & 6.4 \\
\hline Brazil & 14.3 & $27 / 73$ & 47.3 & 56.3 & 0.7 \\
\hline Chile & 71.7 & $57 / 43$ & 23.4 & 94.1 & 1.9 \\
\hline Colombia & 20.7 & $45 / 55$ & 21.2 & 58.0 & 0.6 \\
\hline Costa Rica & 14.1 & $40 / 60$ & 65.8 & 84.6 & 1.7 \\
\hline Mexico & 12.3 & $21 / 79$ & 66.4 & 68.1 & 3.7 \\
\hline Peru & 20.8 & $22 / 78$ & 18.3 & 25.5 & 0.7 \\
\hline Uruguay & 16.5 & $0 / 100$ & - & 38.2 & 0.9 \\
\hline Mean & 25.9 & $36 / 64$ & 41.6 & 62.0 & 2.1 \\
\hline \multicolumn{6}{|l|}{ East Asia } \\
\hline Indonesia & 40.5 & $44 / 56$ & 0 & 4.3 & 1.0 \\
\hline Japan & 27.7 & $0 / 100$ & - & 67.6 & 31.2 \\
\hline Korea & 47.1 & $66 / 34$ & 34.3 & 81.7 & 53.7 \\
\hline Taiwan & 40.5 & $13 / 87$ & 0 & 25.5 & 19.6 \\
\hline Thailand & 12.5 & $71 / 29$ & 0 & 12.4 & 17.2 \\
\hline Vietnam & 8.2 & $0 / 100$ & - & 0 & 1.5 \\
\hline Mean & 29.4 & $32 / 68$ & - & 31.5 & 20.7 \\
\hline Overall mean & 23.7 & $51 / 49$ & 65.4 & 73.4 & 37.0 \\
\hline
\end{tabular}


Note: No information is available on proportion government-dependent private schools for Austria and France.

Table A2: Controlled private school effects without and with peer group controls

\begin{tabular}{lcccc}
\hline & \multicolumn{2}{c}{ Private-dependent vs. Public schools } & \multicolumn{2}{c}{ Independent vs. Public schools } \\
\cline { 2 - 5 } & Without & With & Without & With \\
\hline OECD & 0.092 & 0.004 & 0.236 & 0.073 \\
\hline MENA & $0.053^{*}$ & $-0.125^{*}$ & 0.340 & 0.208 \\
\hline South America & 0.180 & -0.031 & 0.420 & 0.102 \\
\hline East Asia & -0.327 & -0.234 & -0.311 & -0.324 \\
\hline Overall mean & $\mathbf{0 . 0 5 7}$ & $\mathbf{- 0 . 0 3 8}$ & $\mathbf{0 . 1 8 8}$ & $\mathbf{0 . 0 1 7}$ \\
\hline
\end{tabular}

* Only UAE in the group. 